\title{
The Effect of Anemia on Quality of Life and Self-Care Agency in Turkey Hemodialysis Patients
}

\author{
Besey Ören', Neriman Zengin ${ }^{2}$ \\ ${ }^{1}$ Midwifery Department, Health Sciences Faculty, University of Health Sciences, İstanbul, Turkey \\ ${ }^{2}$ Midwifery Department, Health Science Faculty, Istanbul University, İstanbul, Turkey \\ Email: besey_oren@yahoo.com,nzengin@istanbul.edu.tr
}

Received 5 May 2016; accepted 6 June 2016; published 9 June 2016

Copyright (C) 2016 by authors and Scientific Research Publishing Inc.

This work is licensed under the Creative Commons Attribution International License (CC BY).

http://creativecommons.org/licenses/by/4.0/

cc) (i) Open Access

\begin{abstract}
Objective: Anemia is an important complication which affects quality of life and self-care agency in hemodialysis patients. The aim of this study was to determine the effects of anemia on quality of life and self-care agency in adult patients who receive chronic hemodialysis treatment. Methods: In this cross-sectional study, the Quality of Life Scale, the Self Care Agency Scale, and a data form were administered to 136 hemodialysis patients who were receiving treatment three hospitalbased dialysis units in Istanbul. Results: The health perception of cases whose hemoglobin level was $12 \mathrm{mg} / \mathrm{dl}$ and above was significantly better than those whose hemoglobin level was lower than $12 \mathrm{mg} / \mathrm{dl}$. Hemoglobin levels were significantly and positively correlated to physical role function, general health, and health from the previous year $(p<0.05)$. As the hemoglobin levels of the cases increased, quality of life pertaining to the mentioned domains increased. Conclusion: It was concluded that the quality of life in chronic dialysis patients was affected by anemia.
\end{abstract}

Keywords

Anemia, Nursing Care, Hemodialysis, Self-Care Agency, Quality of Life

\section{Introduction}

The most common renal replacement treatment (RRT) method used in Turkey is hemodialysis (HD). The distribution of patients who started to receive RRT in 2014 according to the type of RRT shows that $78.37 \%(55,890)$ of the patients received hemodialysis (HD) [1]. According to this data, Turkey ranks fifth among European countries in terms of patient populations receiving HD treatment [2]. 
Anemia is a common problem among HD patients. In chronic renal failure patients, renal cells responsible for EPO production or regulation are damaged, resulting in hypoproliferative anemia [3] [4]. In addition, chronic inflammation and deficiency of vitamins, iron deficiency, hemolysis, uremic toxins, insufficient dialysis, aluminum accumulation, hyperparathyroid, and folic acid deficiency related to erythropoietin contribute to the development of anemia in HD patients [3].

Anemia is the reduced oxygen carrying capacity of red blood cells, which leads to insufficiencies in meeting the physical needs of tissues. The definition for anemia varies by age, gender, and pregnancy status. Reference values pertaining to anemia and its treatment are used in dialysis patients. A Hemoglobin (HGB) level less than $12 \mathrm{~g} / \mathrm{dl}$ in a dialysis patient indicates anemia. Values below $11 \mathrm{~g} / \mathrm{dl}$ necessitate anemia treatment. In most dialysis patients, anemia is severe and requires treatment. In $60 \%$ of patients who start HD treatment, the hematocrit level is $<30 \%$ [5]. Previous studies show that HGB level is related to mortality risk and to the frequency of hospitalization [6]-[8].

Anemia is various symptoms related to anemia including difficulty in respiration, fatigue, and sexual desire disorders can be present [5]. These symptoms may cause insomnia, depression, cognitive function disorders, decreased libido, and left ventricle hypertrophy in case they are not treated [8]-[10]. In addition, anemia increases the need for blood transfusion, the need for hospitalization, and death risk in these patients. High prevalence of depression and sexual dysfunctions in dialysis patients can be partly attributed to this clinical picture [10] [11]. All of these problems related to anemia cause physical, psychological, and socioeconomic problems and thus negatively affect quality of life (QOL) and self-care agency [11]-[13].

Quality of life refers to one's general evaluation of good and satisfying aspects of life [14]-[16]. If an individual is happy and satisfied with his/her life, his/her quality of life can presumed to be good [17] [18]. The aim of health professionals in terms of treatment of chronic diseases and nursing care is to plan and do what is necessary for a patient to maintain a good quality of life as well as increasing the duration of survival [18] [19]. Parameters that have a negative impact on quality of life should be detected and eliminated in order to help patients maintain a good quality of life. Many researchers emphasize that an improvement in QOL reduces the complications associated with a disease, or at least makes such complications more tolerable [9]-[12] [16]. Selfcare agency encompasses an individual's cognitive, physical, psychological and behavioral domains [11] [18]. Self-care agency is a key component of healthcare and it distinguishes nursing from other disciplines. Self-care agency is considered to be a nursing outcome [19].

Self-care agency is an individual's continuous contribution to his/her own health [19] [20]. In dialysis, similar to most chronic diseases which involve a deviation from health, an individual's self-care needs usually surpass his/her self-care agency [20].

Anemia is a common condition in HD patients and is related to poor outcomes. Anemia has a negative effect on patients' QOL and self-care agency. As the severity of anemia increases, the effect of anemia on self-care agency and QOL also increase. Therefore, it is important to achieve successful management of anemia in such patients [19] [21]-[25]. In order to achieve this, the most affected domains of a patient's quality of life and selfcare agency should be determined. Although there are a limited number of studies that separately investigate QOL and self-care agency in HD patients in Turkey, there were no studies investigating the effect of anemia on QOL and self-care agency using a disease specific scale.

\section{Methods}

This prospective and cross-sectional study was conducted to determine the effect of anemia on quality of life and self-care agency in hemodialysis patients. The potential participants of the study included all patients receiving treatment at three hemodialysis units in Istanbul between May 1 and December 27, 2013 during 8-month period. The sample consisted of $136 \mathrm{HD}$ patients who were literate, older than 18 years of age and agreed to voluntarily participate in the study. Since this study was conducted with chronic dialysis patients, those who have been receiving hemodialysis treatment for less than 6 months were excluded. The sample was selected according to a $5 \%$ error rate and a $95 \%$ confidence interval. In this study, the criterion $\mathrm{Hb} \leq 12 \mathrm{gr} / \mathrm{dl}$ was accepted in order to detect anemia [5].

Data was collected using the patient information form, the SF-36 Quality of Life Scale, and the Self-Care Agency Scale (SCAS) was developed by Oren and Enc and was found to be valid and reliable in chronic dialysis patients in Turkey [14]. In this study, the Cronbach alpha value of the SCAS was found to be 0.74. Participants 
were asked to read each item and report his/her self-care behavior in daily situations by marking one of the choices. In addition, laboratory data pertaining to the patients were collected from medical charts during the same period.

All statistical calculations were performed using SPSS statistical software (version 15.0, SPSS Inc.,Chicago, IL, USA). Data was analyzed using percentages, minimum and maximum values, standard deviations, independent samples t-test, Kruskall Wallis test, Mann-Whitney U test, and Pearson correlation analysis. $p<0.05$ was considered statistically significant for all tests. The study was approved by the Ethics Committee of Istanbul University in Turkey. The research was conducted in line with the rules of the Helsinki Declaration.

\section{Results}

The mean age of the cases was $47.38 \pm 15.27$ (20 - 81) and mean duration of dialysis was $7.85 \pm 5.0$ years. Among the cases, $57.4 \%$ were male, $65.4 \%$ were married, $54.4 \%$ were primary school graduates, $67 \%$ were unemployed, $77.2 \%$ had a nuclear family, $75.7 \%$ reported that they received support from their families, and $56.6 \%$ had a moderate level of income. It was found that 31.6\% of the patients had Hepatitis C, $20.6 \%$ had hypertension (HT), $11.8 \%$ had Hepatitis B, and $8.1 \%$ had heart disease. Mean HGB was $11.45 \pm 1.76$ (6.60 18.90). It was determined that $58.1 \%$ of the group used EPO. Among the group who used EPO, $54.4 \%$ received additional iron pills. It was found that $90.6 \%$ of the group $(n=53)$ whose hemoglobin level was 11 and lower used EPO.

According to statistical analyses, there were no significant differences in anemia status according to age, gender, marital status, family structure, and occupation $(p>0.05)$. However, it was found that the HGB levels of the group whose duration of dialysis was 10 years and more were significantly high $(p=0.03)$.

When quality of life in anemic and non-anemic patients was examined, it was found that the health from the previous year dimension of S-36 Quality of Life Scale showed significant differences at $p<0.05$ level $\left[\mathrm{t}_{(136)}=\right.$ 2.22, $p=0.028$ ]. According to this, the group whose HGB level was above $12 \mathrm{gr} / \mathrm{dl}$ obtained higher scores (Table 1).

When self-care agency was examined according to the presence of anemia, it was determined that the non-anemic group obtained higher scores in all subscales compared to the anemic group; however, these differences between two groups were not statistically significant (Table 1 ).

HGB level was positively correlated with physical role function $(\mathrm{r}=0.18, p=0.02)$, emotional role function ( $r=0.17, p=0.04)$, and general health $(r=0.17, p=0.03)$ subscales of the SF-36, and negatively correlated with health from the previous year $(r=-0.19, p=0.02)$. However, there were no significant correlations between HGB levels and SCAS subscales (Table 2).

\section{Discussion}

Anemia can affect patients' quality of life and self-care agency. Literature and shows that anemia is a common problem in HD patients [4] [5] [11].

In studies which examine the association between anemia and quality of life in HD patients, contradictory results have been obtained. A number of studies reported that anemia has negative effects on all quality of life domains [24]. In a distinctive study, it was found that anemia had negative effects on only the physical and mental domains of quality of life [23]. On the other hand, some studies reported that there is no significant relationship between quality of life and HGB [24]. In our study; all physical, social, emotional, fatigue, pain, general health, and health from previous year dimensions of quality of life except for the mental health were better in cases whose HGB was $\geq 12$ but these differences were not statistically significant (Table 1 ). This result is consistent with Kring and Crane’s findings (2009) in terms of the mental health dimension and with Guney's (2005) findings in terms of other dimensions of quality of life [22] [24].

Anemia has a negative effect on functional capacity [11] [15] [16]. It can be claimed that patients who feel physically weak are also affected mentally. Therefore, it is natural for cases whose HGB level is above 12 to attain higher scores from quality of life dimensions. In addition, it was expected to find positive correlations between HGB and physical role function, emotional role function, general health, and health from the previous year $(p<0.05)$.

There are only a limited number of studies on self-care agency and HD in Turkey. A Turkish study, it was found that HD practices had negative effects on patients' self-care agency [19]; whereas in another study, it was 
Table 1. Quality of life and self-care agency by presence of anemia $(\mathrm{n}=136)$.

\begin{tabular}{|c|c|c|c|}
\hline SF-36 Subscales & $\begin{array}{c}\text { HGB } \\
\geq 12(n=46) \\
<12(n=90)\end{array}$ & $\mathrm{X} \pm \mathrm{SS}$ & $\begin{array}{l}\mathrm{t}^{*} \\
p\end{array}$ \\
\hline \multirow{2}{*}{ Physical function } & $\geq 12$ & $66.53 \pm 23.10$ & -1.254 \\
\hline & $<12$ & $60.89 \pm 23.10$ & 0.212 \\
\hline \multirow{2}{*}{ Social function } & $\geq 12$ & $68.16 \pm 26.58$ & -1.755 \\
\hline & $<12$ & $59.25 \pm 29.99$ & 0.081 \\
\hline \multirow{2}{*}{ Physical role-function } & $\geq 12$ & $46.15 \pm 42.69$ & -1.760 \\
\hline & $<12$ & $33.33 \pm 40.39$ & 0.081 \\
\hline \multirow{2}{*}{ Emotional role-function } & $\geq 12$ & $50.64 \pm 40.95$ & -1715 \\
\hline & $<12$ & $38.09 \pm 41.76$ & 0.089 \\
\hline \multirow{2}{*}{ Mental health } & $\geq 12$ & $63.29 \pm 18.95$ & -0.119 \\
\hline & $<12$ & $63.47 \pm 22.48$ & 0.905 \\
\hline \multirow{2}{*}{ Vitality-Fatique } & $\geq 12$ & $52.11 \pm 23.68$ & -1.005 \\
\hline & $<12$ & $47.91 \pm 23.65$ & 0.317 \\
\hline \multirow{2}{*}{ Bodily pain } & $\geq 12$ & $64.74 \pm 29.58$ & 0.859 \\
\hline & $<12$ & $60.31 \pm 28.97$ & 0.392 \\
\hline \multirow{2}{*}{ General health } & $\geq 12$ & $49.34 \pm 20.07$ & -1292 \\
\hline & $<12$ & $44.85 \pm 19.45$ & 0.199 \\
\hline \multirow{2}{*}{ Health from the previous year } & $\geq 12$ & $51.48 \pm 23.39$ & 2.220 \\
\hline & $<12$ & $42.30 \pm 23.50$ & $0.028^{* *}$ \\
\hline \multicolumn{4}{|l|}{ Self Care Agency Subscales } \\
\hline \multirow{2}{*}{ Use of medicine } & $\geq 12$ & $8.48 \pm 2.50$ & 0.945 \\
\hline & $<12$ & $8.86 \pm 2.21$ & 0.346 \\
\hline \multirow{2}{*}{ Diet } & $\geq 12$ & $6.65 \pm 1.59$ & -0.618 \\
\hline & $<12$ & $6.46 \pm 1.82$ & 0.537 \\
\hline \multirow{2}{*}{ Self-monitoring } & $\geq 12$ & $4.71 \pm 1.82$ & -0.862 \\
\hline & $<12$ & $4.41 \pm 2.00$ & 0.390 \\
\hline \multirow{2}{*}{ Hygienic care } & $\geq 12$ & $7.01 \pm 1.03$ & -0.923 \\
\hline & $<12$ & $6.81 \pm 1.41$ & 0.357 \\
\hline \multirow{2}{*}{ Mental state } & $\geq 12$ & $3.76 \pm 1.07$ & -1.695 \\
\hline & $<12$ & $3.44 \pm 1.11$ & 0.092 \\
\hline
\end{tabular}

*Independent samples t-test analysis, ${ }^{* *} p<0.05$.

Table 2. The relationship of hemoglobin level to quality of life and self-care agency $(n=136)$.

\begin{tabular}{|c|c|c|c|}
\hline & & \multicolumn{2}{|c|}{ Hemoglobin } \\
\hline & & $\mathrm{r}$ & $p$ \\
\hline & Physical function & 0.092 & 0.28 \\
\hline & Social function & 0.083 & 0.33 \\
\hline & Physical role-function & $0.18^{*}$ & 0.02 \\
\hline \multirow[t]{6}{*}{ SF-36 Subscales } & Emotional role-function & $0.17^{*}$ & 0.04 \\
\hline & Mental health & 0.04 & 0.62 \\
\hline & Vitality-Fatique & 0.11 & 0.19 \\
\hline & Bodily pain & 0.11 & 0.19 \\
\hline & General health & $0.17^{*}$ & 0.03 \\
\hline & Health from the previous year & $-0.19^{*}$ & 0.02 \\
\hline
\end{tabular}




\section{Continued}

\begin{tabular}{lccc}
\hline & Use of Medicine & 0.03 & 0.72 \\
Self Care Agency Subscale & Diet & 0.06 & 0.46 \\
& Self-monitoring & 0.10 & 0.22 \\
& Hygienic care & 0.04 & 0.60 \\
& Mental state & 0.09 & 0.26 \\
\hline
\end{tabular}

Pearson correlation, ${ }^{*} p<0.05$.

reported that more studies needed to be conducted on HD and self-care agency [23]. There were no studies investigating the relationship between anemia and self-care agency using a disease specific scale. In the present study, no association found between anemia and self-care agency (Table 1 and Table 2).

Erythropoietin and iron treatment are the main components of renal anemia treatment [25]. It has been reported that treating anemia improves patients' quality of life and oxygenation, and in turn, improves self-care agency and prevents bleeding by affecting thrombocyte functions [5] [19] [24]. According to this results can be said the HGB level is a good indicator of working capacity and quality of life.

\section{Conclusion and Suggestions}

This study has shown that anemia has negative effects on many dimensions of quality of life in chronic hemodialysis patients. However, it was found that anemia did not affect self-care agency levels. The study draws nurses' attention to the negative effects of anemia. Dialysis nurses plan appropriate nursing care according to these results.

\section{Authors' Contribution}

BÖ and NZ conceived, designed and did statistical analysis \& editing of manuscript. BÖ did data collection and manuscript writing. BÖ and NZ did review and final approval of manuscript.

\section{Grant Support \& Financial Disclosures}

None.

\section{References}

[1] Süleymanlar, G., Ateş, K. and Seyahi, N. (2014) Turkish Society of Nephrology. Registry of the Nephrology, Dialysis and Transplantation in Turkey, Istanbul. (In Turkish)

[2] Erek, E., Süleymanlar, G. and Serdengeçti, K. (2002) Nephrology, Dialysis and Transplantation in Turkey. Nephrology Dialysis Transplantation, 17, 2087-2093. http://dx.doi.org/10.1093/ndt/17.12.2087

[3] Pruett, B., Johnson, S. and O’Keefe, N. (2007) Improving IV Iron and Anemia Management in the Hemodialysis Setting: A Collaborative CQI Approach [Corrected]. Nephrology Nursing Journal, 34, 356.

[4] Mollaoğlu, M. (2015) Anemia and Coagulation Disorders in Dialysis Patients. In: Gökdoğan, F., Ed., Dialysis Principles and Techniques, Ankara, Akademisyen Tip Kitabevi, 237-244. (In Turkish)

[5] National Clinical Guideline Centre (2011) Anaemia Management in Chronic Kidney Disease Clinical Guideline. Update Commissioned by the National Institute for Health and Clinical Excellence, London.

[6] Yang, W., Israni, R.K., Brunelli, S.M., Joffe, M.M., Fishbane, S. and Feldman, H.I. (2007) Hemoglobin Variability and Mortality in ESRD. Journal of the American Society of Nephrology, 18, 3164-3170. http://dx.doi.org/10.1681/ASN.2007010058

[7] Lacson Jr., E. Wang, W., Hakim, R.M., Teng, M. and Lazarus, J.M. (2009) Associates of Mortality and Hospitalization in Hemodialysis: Potentially Actionable Laboratory Variables and Vascular Access. American Journal of Kidney Diseases, 53, 79-90. http://dx.doi.org/10.1681/ASN.2007010058

[8] Cibulka, R. and Racek, J. (2007) Metabolic Disorders in Patients with Chronic Kidney Failure. Physiological Research, 56, 697-705.

[9] Franke, G.H., Reimer, J., Philipp, T. and Heemann, U. (2003) Aspects of Quality of Life through End-Stage Renal Disease. Quality of Life Research, 12, 103-115. http://dx.doi.org/10.1023/A:1022238707028 
[10] Amin, M.G., Tighiouart, H., Weiner, D.E., Stark, P.C., Griffith, J.L., MacLeod, B., et al. (2004) Hematocrit and Left Ventricular Mass: The Framingham Heart Study. Journal of American Collage of Cardiology, 43, 1276-1282. http://dx.doi.org/10.1016/j.jacc.2003.10.048

[11] Ören, B. and Enç, N. (2013) Quality of Life in Chronic Haemodialysis and Peritoneal Dialysis Patients in Turkey and Related Factors. International Journal of Nursing Practice, 19, 547-556. http://dx.doi.org/10.1111/ijn.12098

[12] Yu, I.C., Huang, J.Y. and Tsai, Y.F. (2012) Symptom Cluster among Hemodialysis Patients in Taiwan. Applied Nursing Research, 25, 190-196. http://dx.doi.org/10.1016/j.apnr.2010.11.002

[13] Weiss, G. (2009) Iron Metabolism in the Anemia of Chronic Disease. Biochimica at Biophysica Acta, 7, $682-693$. http://dx.doi.org/10.1016/j.bbagen.2008.08.006

[14] Ören, B. and Enc, N. (2014) Development and Psychometric Testing of the Self-Care Agency Scale for Patients Undergoing Long-Term Dialysis in Turkey. Journal of Renal Care, 4, 266-273. http://dx.doi.org/10.1111/jorc.12098

[15] Santos, P.R., Daher, E.F., Silvia, G.B., Liborio, A.B. and Kerr, L.R. (2009) Quality of Life Assessment among Haemodialysis Patients in a Single Centre: A 2-Year Follow-Up. Quality of Life Research, 5, 541-546. http://dx.doi.org/10.1007/s11136-009-9474-2

[16] Mau, L.W., Chiu, H.C., Chang, P.Y., Hwang, S.C. and Hwang, S.J. (2008) Health-Related Quality of Life in Taiwanese Dialysis Patients: Effects of Dialysis Modality. The Kaohsiung Journal of Medical Sciences, 24, 453-460. http://dx.doi.org/10.1016/S1607-551X(09)70002-6

[17] Nabolsi, M.M., Wardam, L. and Al-Halabi, J.O. (2015) Quality of Life, Depression, Adherence to Treatment and Illness Perception of Patients on Haemodialysis. International Journal of Nursing Practice, 21, 1-10. http://dx.doi.org/10.1111/ijn.12205

[18] Zengin, N., Oren, B., Gul, A. and Ustundag, H. (2014) Assessment of Quality of Life in Haemodialysis Patients: A Comparison of the Nottingham Health Profile and the Short Form 36. International Journal of Nursing Practice, 20, 115-125. http://dx.doi.org/10.1111/ijn.12130

[19] Bağ, E. and Mollaoğlu, M. (2010) The Evaluation of Self-Care and Self-Efficacy in Patients Undergoing Hemodialysis. Journal of Evaluation in Clinical Practice, 16, 605-610.

[20] Li, H., Jiang, Y.F. and Lin, C.C. (2014) Factors Associated with Self-Management by People Undergoing Hemodialysis: A Descriptive Study. International Journal of Nursing Studies, 51, 208-216. http://dx.doi.org/10.1016/j.ijnurstu.2013.05.012

[21] Rodríguez-Artalejo, F., Guallar-Castillón, P., Pascual, C.R., Otero, C.M., Montes, A.Q., Garcia A.N., Conthe, P., Chiva, M.O., Banegas, J.R. and Herrera, M.C. (2005) Health Related Quality of Life as a Predictor of Hospital Readmission and Death among Patients with Heart Failure. Archives of International Medicine, 165, 1274-1279.

[22] Kring, D.L. and Crane, P.B. (2009) Factors Affecting Quality of Life in Persons on Hemodialysis. Nephrology Nursing Journal, 36, 15-24.

[23] Richard, C.J. (2006) Self-Care Management in Adults Undergoing Hemodialysis. Nephrology Nursing Journal, 33, 387-394.

[24] Güney, I., Altıntepe, L., Türk, S., Atalay, H., Tonbul, H.Z. and Yeksan, M. (2005) The Evaluation of Demographical, Clinical and Laboratory Characteristics and the Factors that Influence Health-Related Quality of Life in Hemodialysis Patients in Konya. Turkish Nephrology, Dialysis and Transplantation Journal, 14, 26-31. (In Turkish)

[25] Palmer, S.C., Nand, K., Dwi Nur Hidayati, L., Munasinghe, A., Nelson, C., Khafaji, M.M.H. and Strippoli, G.F.M. (2012) Continuous Erythropoiesis Receptor Activator (CERA) for the Anaemia of Chronic Kidney Disease (Protocol). Cochrane Database of Systematic Reviews, No. 6, Article No. CD009904. http://onlinelibrary.wiley.com/doi/10.1002/14651858.CD009904/pdf 